\title{
Sciendo
}

\author{
BULGARIAN ACADEMY OF SCIENCES
}

CYBERNETICS AND INFORMATION TECHNOLOGIES • Volume 19, No 2

Sofia • $2019 \quad$ Print ISSN: 1311-9702; Online ISSN: 1314-4081

DOI: $10.2478 /$ cait-2019-0016

\section{Fuzzy Supervised Multi-Period Time Series Forecasting}

\section{Galina Ilieva}

Paisii Hilendarski, University of Plovdiv, 4000 Plovdiv, Bulgaria

E-mail: galili@uni-plovdiv.bg

\begin{abstract}
The goal of this paper is to propose a new method for fuzzy forecasting of time series with supervised learning and k-order fuzzy relationships. In the training phase based on $k$ previous historical periods, a multidimensional matrix of fuzzy dependencies is constructed. During the test stage, the fitted fuzzy model is run for validating the observations and each output value is predicted by using a fuzzy input vector of $k$ previous intervals. The proposed algorithm is verified by a benchmark dataset for fuzzy time series forecasting. The results obtained are similar or better than those of other fuzzy time series prediction methods. Comparative analysis shows the high potential of the new algorithm as an alternative to fuzzy prediction and reveals some opportunities for its further improvement.
\end{abstract}

Keywords: Fuzzy set, fuzzy time series, forecasting, membership function, fuzzy relationships.

\section{Introduction}

The purpose of this paper is to suggest, analyze and assess a new supervised machinelearning algorithm for Time Series (TS) prediction with Fuzzy Transition Relationships Matrix (FTRM). Examining a training dataset with a sliding window of size $k$, the new method calculates a cumulative $k$-dimensional fuzzy matrix of transition dependencies (training period).

Then, in the second test period, using the new model, for each $k$ consecutive elements from the test dataset, the next output value is obtained. The proposed algorithm is verified on a stock index benchmarking dataset. Comparative analysis of obtained prognostic values demonstrates that the new FTRM model is a feasible and flexible alternative to other Fuzzy Time Series (FTS) prediction models.

Time series analysis and forecasting are of particular importance in economics, engineering, biology, medicine, meteorology and a number of other fields. Regarding the complex and volatile nature of market prices, classical statistical methods, such as classification and regression, are poor choices in building an adequate model for non-linear stock exchanges. A major disadvantage of statistical models is that they cannot reveal hidden patterns of variations between price values. 
The term "fuzzy time series" was coined by S ong and Chissom [25]. Nowadays it includes various approaches and algorithms for forecasting fuzzy time series. Fuzzy sets approaches have been successfully implemented in various research domains [9-13, 16-24, 27]. Logically, they are successfully implemented in time series modeling [14].

In their seminal works, $\mathrm{S}$ o $\mathrm{ng}$ and $\mathrm{C} \mathrm{h}$ i s s o $\mathrm{m}[25,26]$ build several predictive methods based on fuzzy relations between every two consecutive observations. Replacing complicated max-min composition operations from [26] with simplified arithmetic operations, $\mathrm{Ch}$ e n [2] suggests a more efficient method. $\mathrm{Y} \mathrm{u}$ [28] adjusted the lengths of intervals with the use of a dynamic approach - distribution and optimization technique.

In the last decade, intelligent methods such as Artificial Neural Networks (ANN), Genetic Algorithms (GA) and Principal Component Analysis (PCA) are finding an increasing application to solve the task of fuzzy forecasting of time series $[7,8,15]$. C h a n g, W e i and C h e n g [1] propose a hybrid Adaptive Network-based Fuzzy Inference System (ANFIS) model that employs AR and volatility to solve stock price forecast problems. Cheng et al. [4] model implements the Ordered Weighted Averaging (OWA) operator to fuse high-order data into the aggregated values of single attributes and an ANFIS procedure for forecasting stock price. Chen and Jian propose a PSA-based algorithm to get the optimal partition of the intervals in the Universe Of Discourse (UOD) of the main factor TAIEX and to discover the optimal partition of intervals in the UOD of the Secondary Factor (SF), where $\mathrm{SF} \in\{$ Dow Jones, NASDAQ, M1B\}. Based on the proposed PSA-based algorithm, constructed two-factor second-order fuzzy-trend logical relationship groups, and similarity measures between the subscripts of fuzzy sets, they create a new method for predicting the TAIEX and the NTD/USD exchange rates [3].

Meanwhile, improvements in information technologies and falling prices of integrated circuits made it possible to combine classical probability methods with modern fuzzy data processing algorithms. Research continues and involves more advanced forms of fuzzy numbers such as neutrosophic sets $[5,6]$. H. Guan, $\mathrm{S}$. Gu a n and A. Z h a o [5] present new mechanisms for fuzzy neutrosophic logical relation representation and similarity measure to forecast time series fluctuation.

The short review of literature regarding fuzzy time series prediction shows that there is no common model or algorithm that solves this problem. Adoption of fuzzy methods with machine learning will help stock, bonds, derivatives, and forex traders to increase the accuracy and reliability of their decisions. This work develops and validates a new supervised fuzzy model, which performance is equal or exceeds that of previous forecasting methods, due to precisely selected UOD intervals.

The remaining part of this paper is organized as follows. Section 2 briefly introduces the basic concepts of FTS and transition relationships between consecutive time periods. Section 3 presents the peculiarities of the new fuzzy time series forecasting method. Section 4 analyses the empirical results obtained by using different prediction models. The last section concludes the paper. 


\section{Preliminaries}

Definition 1 [15]. Let $L=\left\{l_{1}, l_{2}, \ldots, l_{g}\right\}$ be a fuzzy set in the universe of discourse $U$. It can be defined by its membership function, $\mu_{L}: U \rightarrow[0,1]$, where $\mu_{L}\left(u_{i}\right)$ denotes the grade of membership of $u_{i}, U=\left\{u_{1}, u_{2}, \ldots, u_{i}, \ldots, u_{l}\right\}$.

Definition 2 [15]. Let $F(t) \in \mathbb{R}, t=1,2, \ldots, T$ be a time series, where $T$ is its number of periods. $G(t)$ is defined as a fluctuation time series, where

$$
G(t)=F(t)-F(t-1) \text {. }
$$

Each element of $G(\mathrm{t})$ can be represented by a fuzzy set $S(t), t=2,3, \ldots, T$, as defined in Definition 1. In other words, we "fuzzify" time series $G(t)$ into a FuzzyFluctuation Time Series (FFTS) $S(t)$.

Definition 3 [15]. Let $S(t), t=k+1, k+2, \ldots, T, k \geq 1$, be a FFTS. If $S(t)$ is determined by $S(t-1), S(t-2), \ldots, S(t-k)$, then the fuzzy-fluctuation logical relationship is represented by $k$-th order fuzzy fluctuation:

$$
S(t-1), S(t-2), \ldots, S(t-k) \rightarrow S(t), t \geq k+2 .
$$

Based on Type-1 fuzzy set theory, we propose the concept of fuzzy transition relationship, which employs the fuzzy values from previous time periods to reflect the fuzzy fluctuation trends and variations of an $k$-th order FFTS.

Definition 4. Let

$$
\begin{gathered}
M_{S(t-k)}=\left\{\mu_{S(t-k) 1}, \mu_{S(t-k) 2}, \ldots, \mu_{S(t-k) l}\right\}, \ldots, \\
M_{S(t-2)}=\left\{\mu_{S(t-2) 1}, \mu_{S(t-2) 2}, \ldots, \mu_{S(t-2) l}\right\}, \\
M_{S(t-1)}\left\{\mu_{S(t-1) 1}, \mu_{S(t-1) 2}, \ldots, \mu_{S(t-1) l}\right\}, \ldots, \\
\text { and } M_{S(t)}=\left\{\mu_{S(t) 1}, \mu_{S(t) 2}, \ldots, \mu_{S(t) l}\right\}
\end{gathered}
$$

denote the FFTS $S(t-k), \ldots, S(t-2), S(t-1)$ and $S(t)$. In order to uncover the dependence in price change between periods $t-k, \ldots, t-2, t-1$, and $t$, we calculate the mutual relation between $M_{S(t-k)}, \ldots, M_{S(t-2)}, M_{S(t-1)}$ and $M_{S(t)}$, summing the products obtained using the following formulas:

(2) $\Delta_{i \ldots o p}=M_{S(t)} * \mu_{S(t-k) i} * \ldots * \mu_{S(t-2) o} * \mu_{S(t-1) p}, i, \ldots, o, p=1,2, \ldots, l$,

$$
\mathrm{FTRM}_{i \ldots o p}^{S}=\mathrm{FTRM}_{i \ldots o p}^{S-1}+\Delta_{i, \ldots, o, p} \text {, }
$$

for each $k$ successive periods in the training set. Here the indices $i, \ldots, o p$ number is $k$. After normalization of the last $k$-dimensional matrix of fuzzy Type- 1 numbers, we get final FTRM.

\section{FFTS-FTRM algorithm}

The new FFTS prediction method consists of several main parts: time series data fuzzification, new FTRM model establishment, a model-based FFTS output prediction and finally, defuzzifications of predicted fuzzy time series values into crisp ones. A flowchart of the new algorithm is depicted in Fig. 1.

A detailed step-by-step description of new algorithms can be found below:

Step 1. Enter the time series elements $F(t), t=2,3, \ldots, T$.

Step 2. Calculate the differences between every two adjacent periods $G(t)$, $t=2,3, \ldots, T$. After that, determine the number of intervals $g$ and calculate the 
boundaries of each interval $L$. Let $g=7$ and $L=\left\{l_{1}, l_{2}, \ldots, l_{7}\right\}$. Then define seven levels of fuzziness as follows: $u_{1}=\left(-\infty, l_{2}\right), u_{2}=\left[l_{1}, l_{3}\right), u_{3}=\left[l_{2}, l_{4}\right), u_{4}=\left[l_{3}, l_{5}\right)$, $u_{5}=\left[l_{4}, l_{6}\right), u_{6}=\left[l_{5}, l_{7}\right), u_{7}=\left[l_{6},+\infty\right)$.

\section{Training}

1. Input training time series. Transform time series into a fluctuation time series by using first difference operator.

2. Define the universe of discourse for obtained differences by using an approximately equal number of instances in each interval. Calculate the boundaries of each interval.

3. Set the membership function for each FFTS value.

4. Generate FTRM forecasting model with a sliding window of size $k$.

Testing

5. Predict the test dataset fuzzy output variables by the new model and $k$ previous observations.

6. Defuzzify predicted output values.

7. Evaluate the model's prediction accuracy.

Fig. 1. Flowchart of the supervised fuzzy time series $k$-order prediction algorithm with transition relationships

Step 3. Convert the differences $G(t)$ into their corresponding triangular fuzzy numbers $S(t), t=2,3, \ldots, T$, in a given universe of discourse $U$. The membership degree $\mu_{i}$ of each index value is defined as follows:

$$
\begin{gathered}
\mu_{1}=\left\{\begin{array}{c}
1, x<l_{1}, \\
\frac{l_{2}-x}{l_{2}-l_{1}}, l_{1} \leq x<l_{2}, \\
0, l_{2} \leq x,
\end{array}, \mu_{k}=\left\{\begin{array}{c}
0, x<l_{k-1}, \\
\frac{x-l_{k-1}}{l_{k}-l_{k-1}}, l_{k-1} \leq x<l_{k}, \\
\frac{l_{k+1}-x}{l_{k+1}-l_{k}}, l_{k} \leq x<l_{k+1} \\
0, l_{k+1} \leq x,
\end{array}, k=2, \ldots, 6,\right.\right. \\
\mu_{7}=\left\{\begin{array}{c}
0, \quad x<l_{6}, \\
\frac{x-l_{6}}{l_{7}-l_{6},}, l_{6} \leq x<l_{7}, \\
1, l_{7} \leq x .
\end{array}\right.
\end{gathered}
$$

Step 4. Let FTRM be a fuzzy relationship matrix between each $k$ successive FFTS elements. In case of $k=2$, FTRM is a two-dimensional array of fuzzy numbers with $l$ rows and $l$ columns. Let the first dimension of the matrix correspond to the first factor $S(t-1)$, and the second dimension - to the second factor $S(t-2)$. Let denote $S(t-2), S(t-1)$ and $S(t)$ from FFTS with fuzzy numbers $M_{a}=\left\{\mu_{a 1}, \mu_{a 2}, \ldots, \mu_{a l}\right\}, M_{b}=\left\{\mu_{b 1}, \mu_{b 2}, \ldots, \mu_{b l}\right\}$, and $M_{c}=\left\{\mu_{c 1}, \mu_{c 2}, \ldots, \mu_{c l}\right\}$. To determine the output change over time periods $t-2, t-1$ and $t$, compute the relationship between $M_{a}, M_{b}$ and $M_{c}$ by the next formula:

$$
\Delta_{i j}=M_{c} * \mu_{a i} * \mu_{b j} \text {. }
$$

Add $\Delta_{i j}$ matrix to the current FTRM state according to Equation (3). Repeat Equation (5) and Equation (3) for $t=4,5, \ldots, T$. Normalize the final $\mathrm{FTRM}_{l \times l}$.

Step 5. To forecast next value multiply FTRM and $k$ previous periods values $M_{S(t-k)}, \ldots, M_{S(t-2)}, M_{S(t-1)}$ and $M_{S(t)}$. In case of $k=2$ the equation is:

$$
\mathrm{FTRM}=\mathrm{FTRM} * M_{a} * M_{b}
$$

By using contraction, we convert the result FTRM into a Type-1 fuzzy number: 


$$
\hat{S}(t)=\sum_{i, \ldots, o, p=1}^{l} \text { FTRM. }
$$

Step 6. Defuzzify $\hat{S}(t)$ into $G^{\prime}(t)$, the forecasting value of future fluctuation $G(t)$. Calculate the predicted $F^{\prime}(t+1)$ value by using the following formulae:

$$
F^{\prime}(t+1)=F(t)+G^{\prime}(t) \text {. }
$$

Repeat Step 5 and Step 6 for each element in the test dataset.

Step 7. In order to assess prediction performance, calculate the differences between forecasted actual values. Apply one of the widely used indicator in time series models evaluations - Root of the Mean Squared Error (RMSE), defined as follows:

$$
\operatorname{RMSE}=\sqrt{\frac{\sum_{t=1}^{n}(\text { forecast }(t)-\text { actual }(t))^{2}}{n}} .
$$

An example training and test function pseudocode of the new forecasting FTRM method is shown in Figs 2 and 3.

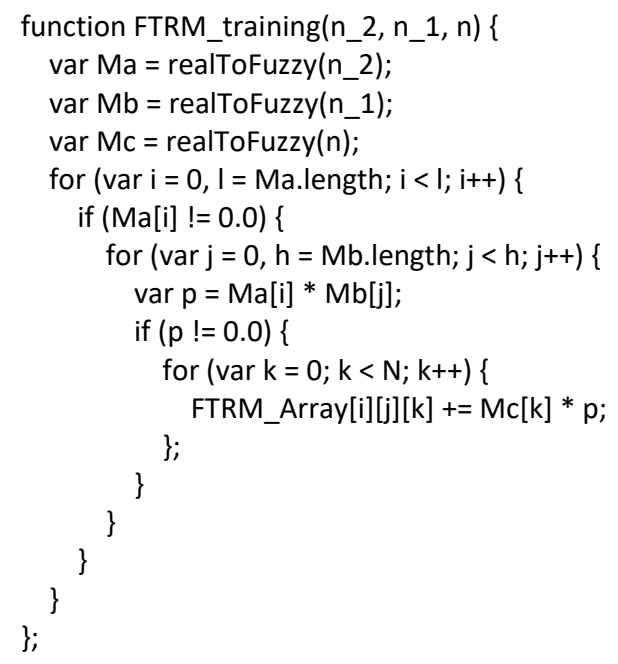

Fig. 2. The training function pseudocode

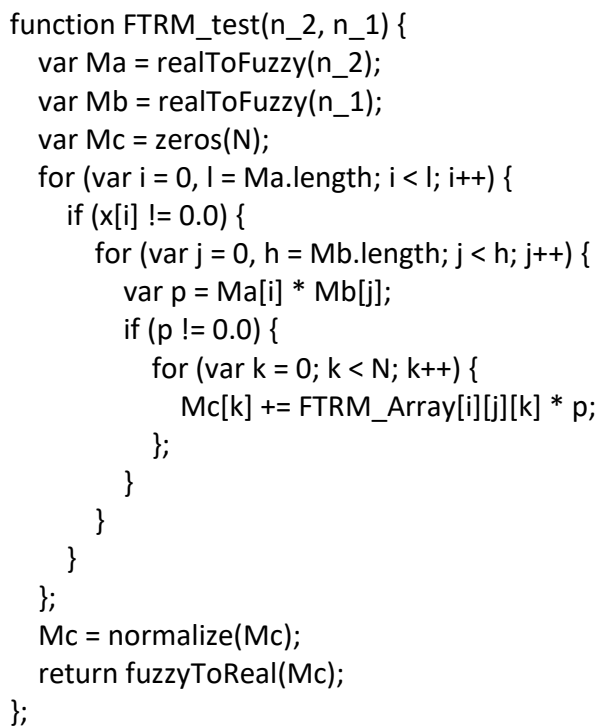

Fig. 3. The test function pseudocode

\section{Numerical example}

In this section, we compute future TAIEX values step by step with the new FTRM method. We also compare the forecasting results of the new method with the ones of other existing methods $[1-5,7-8,15,28]$.

Given: TAIEX Close prices from 01.01.1999 to 31.10.1999

Find: TAIEX forecasting Close prices from 01.11.1999 to 31.12.1999.

Step 1. We used TAIEX data from 01.01.1999 to 31.10.1999 to discover its price patterns. Transform the TAIEX time series into a fluctuation time series (Web Appendix Table A1).

(http://web.uni-plovdiv.bg/galili/FTRM_TAIEX_1999/Web_Appendix.pdf) 
Step 2. In order to define the universe of discourse, we calculate the number of intervals, so all of them contain approximately the same number of observations and obtain that $g=7$. Then we compute the intervals' boundaries: $l_{1}=-110.56, l_{2}=-50.06, l_{3}=-18.91, l_{4}=-0.61, l_{5}=29.24, l_{6}=74.09$, $l_{7}=136.01$. The corresponding $\mu_{i}$ values are depicted in Fig. 4.

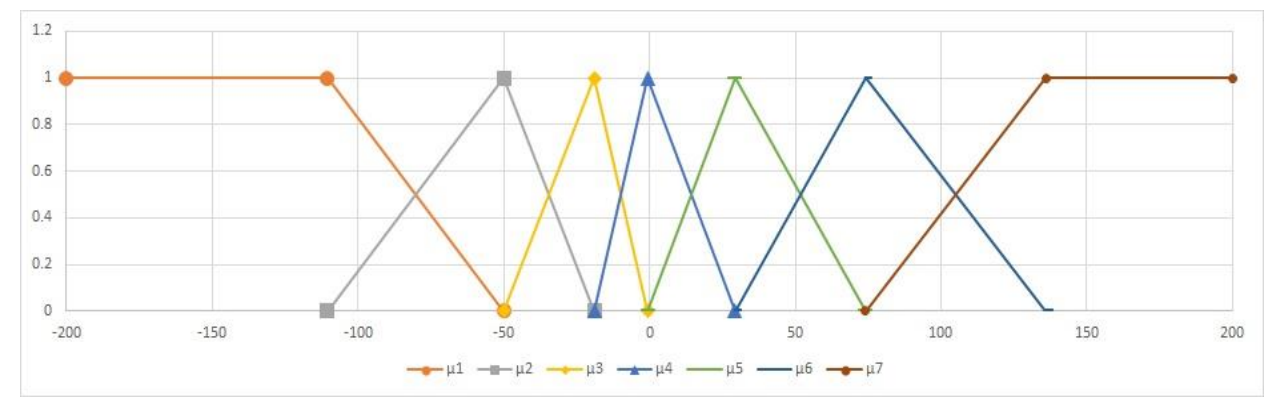

Fig. 4. The membership functions $\mu_{i}, i=1, \ldots, 7$

Step 3. Fuzzify each fluctuation time series value, for example

$F(3)=6404.31$ and $F(4)=6421.75, G(4)=F(4)-F(3)=17.44$, $S(4)=\{0.00,0.00,0.00,0.40,0.60,0.00,0.00\}$.

In this way, all the fuzzified fluctuation dataset were shown in Web Appendix Table A1.

Step 4. According to the new algorithm description, we generate the FTRM and in our experiment $k=2$. From Step 3:

$S(4)=\{0.00,0.00,0.00,0.60,0.40,0.00,0.00\}$, and

$S(5)=\{0.00,0.00,0.77,0.23,0.00,0.00,0.00\}$.

Then we calculate the product $S(4) * S(5)$ and obtain a sparse matrix with four non-zero elements: $0.308,0.092,0.462$ and 0.138 in $i, j$ positions $(4,3) ;(4,4) ;(5,3)$; and $(5,4)$ respectively. After $S(4) * S(5)$ multiplying with $S(6)$ the non-zero FTRM's elements are as follows:

In position $(4,3)=\{0.000,0.240,0.068,0.000,0.000,0.000,0.000\}$,

in position $(4,4)=\{0.000,0.360,0.030,0.000,0.000,0.000,0.000\}$,

in position $(5,3)=\{0.000,0.360,0.102,0.000,0.000,0.000,0.000\}$,

in position $(5,4)=\{0.000,0.108,0.030,0.000,0.000,0.000,0.000\}$.

All results after $221-2$ training steps are shown in Web Appendix Table A2.

Step 5. The forecast value of the TAIEX on November 1, 1999 was computed as follows:

$S_{29.10 .1999}=\{0.00,0.00,0.00,0.15,0.85,0.00,0.00\}$,

$S_{30.10 .1999}=\{0.00,0.00,0.00,0.00,0.00,0.00,1.00\}$.

Then we calculate the product $S_{29.10 .1999} * S_{30.10 .1999}$ and obtain a sparse matrix with two non-zero elements: 0.15 and 0.85 in $i, j$ positions $(4,7)$ and $(5,7)$, respectively. From FTRM forecasting model we get:

In position $(4,7)=\{0.00,0.72,0.91,0.19,0.12,0.14,0.28\}$,

in position $(5,7)=\{0.14,0.88,1.27,1.14,0.98,1.34,0.22\}$. 
After FTRM multiplying with $S_{29.10 .1999} * S_{30.10 .1999}$ we obtain next two fuzzy numbers:

In position $(4,7)=\{0.000,0.108,0.1365,0.0285,0.018,0.021,0.042\}$,

in position $(5,7)=\{0.119,0.748,1.0795,0.969,0.833,1.139,0.187\}$.

Step 6. The fluctuation, obtained by summing of fluctuation fuzzy numbers and normalization is as follows:

$$
\hat{S}(t)=\{-2.424,-7.894,-4.236,-0.112,4.584,15.832,5.738\},
$$

where $t$ is 30.10 .1999 . The defuzzified value is $G^{\prime}(t)=11.488$. Then $F^{\prime}(t+1)=$ $7854.85+11.488=7866.338$. The forecasting results for training dataset are shown in Table 1.

Table 1. Forecasting results from 1 November 1999 to 30 December 1999

\begin{tabular}{|r|r|r|r|r|r|r|r|}
\hline $\begin{array}{c}\text { Date } \\
\text { (DD.MM.YYYY) }\end{array}$ & Actual & Forecast & $\begin{array}{c}\text { (Forecast- } \\
\text { Actual) }\end{array}$ & $\begin{array}{c}\text { Date } \\
\text { (DD.MM.YYYY) }\end{array}$ & Actual & Forecast & $\begin{array}{c}\text { Forecast- } \\
\text { Actual) }\end{array}$ \\
\hline 01.11 .1999 & 7814.89 & 7866.34 & 2646.72 & 01.12 .1999 & 7766.2 & 7772.67 & 41.85 \\
\hline 02.11 .1999 & 7721.59 & 7822.08 & 10097.46 & 02.12 .1999 & 7806.26 & 7771.17 & 1231.22 \\
\hline 03.11 .1999 & 7580.09 & 7718.86 & 19257.13 & 03.12 .1999 & 7933.17 & 7834.84 & 9669.59 \\
\hline 04.11 .1999 & 7469.23 & 7604.20 & 18217.55 & 04.12 .1999 & 7964.49 & 7960.29 & 17.66 \\
\hline 05.11 .1999 & 7488.26 & 7504.69 & 269.80 & 06.12 .1999 & 7894.46 & 7929.95 & 1259.81 \\
\hline 06.11 .1999 & 7376.56 & 7489.95 & 12857.61 & 07.12 .1999 & 7827.05 & 7852.58 & 651.55 \\
\hline 08.11 .1999 & 7401.49 & 7338.37 & 3984.40 & 08.12 .1999 & 7811.02 & 7834.43 & 548.04 \\
\hline 09.11 .1999 & 7362.69 & 7401.97 & 1542.84 & 09.12 .1999 & 7738.84 & 7811.4 & 5264.53 \\
\hline 10.11 .1999 & 7401.81 & 7344.67 & 3265.06 & 10.12 .1999 & 7733.77 & 7757.44 & 560.43 \\
\hline 11.11 .1999 & 7532.22 & 7423.22 & 11880.53 & 13.12 .1999 & 7883.61 & 7733.52 & 22527.63 \\
\hline 15.11 .1999 & 7545.03 & 7557.83 & 163.92 & 14.12 .1999 & 7850.14 & 7899.40 & 2426.88 \\
\hline 16.11 .1999 & 7606.2 & 7525.85 & 6456.39 & 15.12 .1999 & 7859.89 & 7856.90 & 8.96 \\
\hline 17.11 .1999 & 7645.78 & 7607.41 & 1471.96 & 16.12 .1999 & 7739.76 & 7858.77 & 14163.12 \\
\hline 18.11 .1999 & 7718.06 & 7668.75 & 2431.88 & 17.12 .1999 & 7723.22 & 7703.90 & 373.09 \\
\hline 19.11 .1999 & 7770.81 & 7754.67 & 260.36 & 18.12 .1999 & 7797.87 & 7729.82 & 4631.02 \\
\hline 20.11 .1999 & 7900.34 & 7798.9 & 10290.11 & 20.12 .1999 & 7782.94 & 7814.76 & 1012.51 \\
\hline 22.11 .1999 & 8052.31 & 7942.01 & 12165.51 & 21.12 .1999 & 7934.26 & 7797.64 & 18666.26 \\
\hline 23.11 .1999 & 8046.19 & 8059.81 & 185.47 & 22.12 .1999 & 8002.76 & 7967.69 & 1230 \\
\hline 24.11 .1999 & 7921.85 & 8047.44 & 15771.89 & 23.12 .1999 & 8083.49 & 8007.71 & 5742.98 \\
\hline 25.11 .1999 & 7904.53 & 7910.23 & 32.49 & 24.12 .1999 & 8219.45 & 8126.09 & 8715.74 \\
\hline 26.11 .1999 & 7595.44 & 7911.11 & 99644.64 & 27.12 .1999 & 8415.07 & 8278.32 & 18701.53 \\
\hline 29.11 .1999 & 7823.9 & 7619.51 & 41776.96 & 28.12 .1999 & 8448.84 & 8416.74 & 1030.57 \\
\hline 30.11 .1999 & 7720.87 & 7794.3 & 5391.97 & & RMSE & & $\mathbf{9 4 . 1 1}$ \\
\hline & & & & & & & \\
\hline
\end{tabular}

To compare the performance of different FTS methods for prediction we calculate RMSE for forecasting the TAIEX 1999 (Table 2). 
Table 2. Accuracy comparison for TAIEX 1999 prediction

\begin{tabular}{|l|c|}
\hline \multicolumn{1}{|c|}{ Method } & RSME \\
\hline Chen [2] & 120 \\
\hline Y u [28] & 145 \\
\hline H u arng and Y u [8] & 109 \\
\hline H s i e h, H sia o and Y eh [7] & $\mathbf{8 6}$ \\
\hline Ch a n g, We i and Che n g [1] & 100 \\
\hline Che n g et al. [4] & 103 \\
\hline Che n and Ji a n [3] & 99 \\
\hline Ji a, Zh a o and Gu an [15] & 99.12 \\
\hline $\begin{array}{l}\text { H. Gu a n, S. Gu an and A. Zh a o } \\
\text { [5] }\end{array}$ & 99.03 \\
\hline FTRM method & 94.11 \\
\hline
\end{tabular}

Though one of others methods, Hsieh, $\mathrm{H} \mathrm{si}$ a o and $\mathrm{Ye} \mathrm{h}$ [7], has a better result, however, it relies on a computationally intensive programming algorithm (wavelet transformation, regression-correlation selection, neural network training, and artificial bee colony optimization). Our method is relatively simple, but flexible and feasible.

\section{Conclusions}

In this work, a model-based and adaptive fuzzy time series algorithm for $k$-th order forecasting is presented. The machine learning technique enables the efficient training of a model by using hidden statistical dependencies. The robustness of the new algorithm was proven by univariate TAIEX prediction with window size equal to two. Our experiments have shown that the new FTRM method achieves better performance than existing fuzzy prediction models with only one exception.

This study shows that the problem of price index prediction can be solved successfully utilizing the concept of fuzzy time series and a fuzzy matrix of transition relations. The paper demonstrates the application of a type-1 model with a nine-point scale (no influence, very low, low, medium, high, very high, absolutely high) for the TAIEX index dataset. According to the experiments conducted, the number of intervals and their boundaries directly affect prognosis quality. Best results are obtained when all intervals contain the same or approximately equal number of instances. The accuracy of the proposed FTPM predictive method is comparable or superior to that of the existing FTS models;

Our plans about future research include experiment with other input transformation operations (square root, cube root, $\ln , \log$ ) and multivariate input data, check the accuracy of the new model by predicting the prices of other stock indices, and establish the relevance and performance of the model for other types of data (production planning, quality control, marketing, finance). 
Acknowledgements: This research was supported by Education for Smart Growth Operational Programme as a part of projects BG05M2OP001-1.002-0002-C 01.

\section{References}

1. Ch an g, J. R., L. Y. W e i, C. H. Ch en g. A Hybrid ANFIS Model Based on AR and Volatility for TAIEX Forecasting. - Applied Soft Computing Journal, Vol. 11, 2011, Issue 1, pp. 1388-1395.

2. Ch e n, S. M. Forecasting Enrollments Based on Fuzzy Time Series. - Fuzzy Sets and Systems, Vol. 81, 1996, Issue 3, pp. 311-319.

3. Ch e n, S. M., W. S. J i a n. Fuzzy Forecasting Based on Two-Factors Second-Order Fuzzy-Trend Logical Relationship Groups, Similarity Measures and PSO Techniques. - Information Sciences, Vol. 391-392, 2017, pp. 65-79.

4. Cheng, C. H., L. Y. W e i, J. W. Li u, T. L. Chen. OWA-Based ANFIS Model for TAIEX Forecasting. - Economic Modelling, Vol. 30, 2013, Issue 1, pp. 442-448.

5. Gu a n, H., S. G u a n, A. Z h a o. Forecasting Model Based on Neutrosophic Logical Relationship and Jaccard Similarity. - Symmetry, Vol. 9, 2017, Issue 9, 191.

6. Gu a n, H., J. He, Z. D a i, A. Zh a o, S. Gu a n. A Forecasting Model Based on Multi-Valued Neutrosophic Sets and Two-Factor, Third-Order Fuzzy Fluctuation Logical Relationships. Symmetry, Vol. 10, 2018, Issue 7, 245.

7. H s i e h, T. J., H. F. H s i a o, W. C. Y e h. Forecasting Stock Markets Using Wavelet Transforms and Recurrent Neural Networks: An Integrated System Based on Artificial Bee Colony Algorithm. - Applied Soft Computing Journal, Vol. 11, 2011, No 2, pp. 2510-2525.

8. $\mathrm{H} \mathrm{u}$ a r $\mathrm{n}$ g, K. H., T. H. K. Y u. The Application of Neural Networks to Forecast Fuzzy Time Series. - Physica A: Statistical Mechanics and Its Applications, Vol. 336, 2006, Issue 2, pp. 481-491.

9. I 1 i e v a, G. Group Decision Analysis Algorithms with EDAS for Interval Fuzzy Sets. - Cybernetics and Information Technologies, Vol. 18, 2018, No 2, pp. 51-64.

10. I 1 i e v a, G. Group Decision Analysis with Interval Type-2 Fuzzy Numbers. - Cybernetics and Information Technologies, Vol. 17, 2017, No 1, pp. 31-44.

11. I 1 i e va, G. TOPSIS Modification with Interval Type-2 Fuzzy Numbers. - Cybernetics and Information Technologies, Vol. 16, 2016, No 2, pp. 60-68.

12. I l i e va, G., T. Y a n k ova, S. K l i s a rova-B e l c h e va. Decision Analysis with Classic and Fuzzy EDAS Modifications. - Computational and Applied Mathematics, Vol. 37, Issue 5, pp. 5650-5680.

13. I 1 i e va, G. Decision Making Methods in Agent Based Modeling. - In: CEUR Workshop Proceedings, Vol. 752, 2011, pp. 8-17.

14. J a in, S., P. C. Mathpa 1, D. B isht, P. S ingh. A Unique Computational Method for Constructing Intervals in Fuzzy Time Series Forecasting. - Cybernetics and Information Technologies, Vol. 18, 2018, No 1, pp. 3-10.

15. Ji a, J., A. Zh a o, S. Gu a n. Forecasting Based on High-Order Fuzzy-Fluctuation Trends and Particle Swarm Optimization Machine Learning. - Symmetry, Vol. 9, 2017, Issue 7, 124.

16. P e n e va, V., I. P o p c h e v. Aggregation on Fuzzy Numbers in a Decision Making Situation. Cybernetics and Systems, Vol. 32, 2001, Issue 8, pp. 871-885.

17. P e n e va, V., I. P o p ch e v. Fuzzy Criteria Importance Depending on Membership Degrees of Fuzzy Relations. - Compt. Rend. Acad. bulg. Sci., Vol. 61, 2008, No 5, pp. 579-584.

18. P e n e v a, V., I. P o p c h e v. Fuzzy Criteria Importance with Weighting Functions. - Compt. Rend. Acad. bulg. Sci., Vol. 61, 2008, No 3, pp. 293-300.

19. Peneva, V., I. P opchev. Fuzzy Logic Operators in Decision-Making. - Cybernetics and Systems. An International Journal (Editor Robert Trappl), Vol. 30, 1999, No 6, pp. 725-745.

20. P e n e v a, V., I. P o p c h e v. Fuzzy Multi-Criteria Decision Making Algorithms. - Compt. Rend. Acad. bulg. Sci., Vol. 63, 2010, No 7, pp. 979-992.

21. Peneva, V., I. Popchev. Fuzzy Ordering on the Basis of Multicriteria Aggregation. Cybernetics and Systems. An International Journal, Vol. 29, Taylor and Francis (Editor Robert Trappl), 1998, No 6, pp. 613-623. 
22. P e n e v a, V., I. P o p c h e v. Models for Decision Making by Fuzzy Relations and Fuzzy Numbers for Criteria Evaluations. - Compt. Rend. Acad. bulg. Sci., Vol. 62, 2009, No 10, pp. 1217-1222.

23. P op che v, I., V. Pen eva. An Algorithm for Comparison of Fuzzy Sets. - Fuzzy Sets and Systems, Elsevier Science Publishers, North-Holland, Amsterdam, Vol. 60, 1993, No 1, pp. 59-65.

24. R a d e v a, I. Multicriteria Fuzzy Sets Application in Economic Clustering Problems. - Cybernetics and Information Technologies, Vol. 17, 2017, No 3, pp. 29-46.

25. S o n g, Q., B. S. C h i s s o m. Forecasting Enrollments with Fuzzy Time Series. Part I. - Fuzzy Sets and Systems, Vol. 54, 1993, Issue 1, pp. 1-9.

26. S o n g, Q., B. S. Ch i s s o m. Forecasting Enrollments with Fuzzy Time Series. Part II. - Fuzzy Sets and Systems, Vol. 62, 1994, Issue 1, pp. 1-8.

27. S riv a st a v a, P. K., D. B i s h t. Dichotomized Incenter Fuzzy Triangular Ranking Approach to Optimize Interval Data Based Transportation Problem. - Cybernetics and Information Technologies, Vol. 18, 2018, No 4, pp. 111-119.

28. Y u, H. K. Weighted Fuzzy Time Series Models for TAIEX Forecasting. - Physica A: Statistical Mechanics and its Applications, Vol. 349, 2005, Issue 3, pp. 609-624.

\section{Appendix A}

Table A1. Historical training data and fuzzified fluctuation data of TAIEX 1999

\begin{tabular}{|c|c|c|c|c|c|c|c|c|c|c|c|}
\hline Date & & & & Date & & & & Date & & & \\
\hline $\begin{array}{c}\text { (DD. } \\
\text { MM. } \\
\text { YYYY) }\end{array}$ & TAIEX & $\begin{array}{l}\text { tua- } \\
\text { tion }\end{array}$ & fied & $\begin{array}{c}\text { (DD. } \\
\text { MM. } \\
\text { YYYY) }\end{array}$ & TAIEX & $\begin{array}{l}\text { tua- } \\
\text { tion }\end{array}$ & $\begin{array}{l}\text { zi- } \\
\text { fied }\end{array}$ & $\begin{array}{c}\text { (DD. } \\
\text { MM. } \\
\text { YYYY) }\end{array}$ & TAIEX & $\begin{array}{l}\text { tua- } \\
\text { tion }\end{array}$ & $\begin{array}{l}\text { zi- } \\
\text { fied }\end{array}$ \\
\hline 05.01.1999 & 6152.43 & & & 01.02.1999 & 5862.79 & -135.53 & 2 & 08.03.1999 & 6431.96 & 10.23 & 4 \\
\hline 06.01 .1999 & 6199.91 & 47.48 & 5 & 02.02 .1999 & 5749.64 & -113.15 & 3 & 09.03.1999 & 6493.43 & 61.47 & 5 \\
\hline 07.01.1999 & 6404.31 & 204.4 & 6 & 03.02.1999 & 5743.86 & -5.78 & 4 & 10.03 .1999 & 6486.61 & -6.82 & 4 \\
\hline 08.01.1999 & 6421.75 & 17.44 & 4 & 04.02 .1999 & 5514.89 & -228.97 & 1 & 11.03 .1999 & 6436.8 & -49.81 & 3 \\
\hline 11.01.1999 & 6406.99 & -14.76 & 4 & 05.02.1999 & 5474.79 & -40.1 & 4 & 12.03 .1999 & 6462.73 & 25.93 & 4 \\
\hline 12.01.1999 & 6363.89 & -43.1 & 3 & 06.02.1999 & 5710.18 & 235.39 & 7 & 15.03.1999 & 6598.32 & 135.59 & 6 \\
\hline 13.01 .1999 & 6319.34 & -44.55 & 3 & 08.02.1999 & 5822.98 & 112.8 & 5 & 16.03 .1999 & 6672.23 & 73.91 & 5 \\
\hline 14.01 .1999 & 6241.32 & -78.02 & 3 & 09.02.1999 & 5723.73 & -99.25 & 3 & 17.03.1999 & 6757.07 & 84.84 & 5 \\
\hline 15.01 .1999 & 6454.6 & 213.28 & 7 & 10.02.1999 & 5798 & 74.27 & 5 & 18.03.1999 & 6895.01 & 137.94 & 6 \\
\hline 16.01 .1999 & 6483.3 & 28.7 & 4 & 20.02.1999 & 6072.33 & 274.33 & 7 & 19.03.1999 & 6997.29 & 102.28 & 5 \\
\hline 18.01 .1999 & 6377.25 & -106.05 & 3 & 22.02.1999 & 6313.63 & 241.3 & 7 & 20.03.1999 & 6993.38 & -3.91 & 4 \\
\hline 19.01.1999 & 6343.36 & -33.89 & 4 & 23.02.1999 & 6180.94 & -132.69 & 2 & 22.03 .1999 & 7043.23 & 49.85 & 5 \\
\hline 20.01 .1999 & 6310.71 & -32.65 & 4 & 24.02.1999 & 6238.87 & 57.93 & 5 & 23.03 .1999 & 6945.48 & -97.75 & 3 \\
\hline 21.01.1999 & 6332.2 & 21.49 & 4 & 25.02.1999 & 6275.53 & 36.66 & 4 & 24.03.1999 & 6889.42 & -56.06 & 3 \\
\hline 22.01 .1999 & 6228.95 & -103.25 & 3 & 26.02.1999 & 6318.52 & 42.99 & 5 & 25.03 .1999 & 6941.38 & 51.96 & 5 \\
\hline 25.01 .1999 & 6033.21 & -195.74 & 2 & 01.03.1999 & 6312.25 & -6.27 & 4 & 26.03 .1999 & 7033.25 & 91.87 & 5 \\
\hline 26.01.1999 & 6115.64 & 82.43 & 5 & 02.03.1999 & 6263.54 & -48.71 & 3 & 29.03.1999 & 6901.68 & -131.57 & 2 \\
\hline 27.01 .1999 & 6138.87 & 23.23 & 4 & 03.03.1999 & 6403.14 & 139.6 & 6 & 30.03 .1999 & 6898.66 & -3.02 & 4 \\
\hline 28.01 .1999 & 6063.41 & -75.46 & 3 & 04.03 .1999 & 6393.74 & -9.4 & 4 & 31.03 .1999 & 6881.72 & -16.94 & 4 \\
\hline 29.01.1999 & 5984 & -79.41 & 3 & 05.03.1999 & 6383.09 & -10.65 & 4 & 01.04.1999 & 7018.68 & 136.96 & 6 \\
\hline 30.01.1999 & 5998.32 & 14.32 & 4 & |06.03.1999 & 6421.73 & 38.64 & 4 & 02.04 .1999 & 723251 & 213.83 & 7 \\
\hline
\end{tabular}


Table A1 (c o n t i n u e d)

\begin{tabular}{|c|c|c|c|c|c|c|c|c|c|c|c|}
\hline \multirow{2}{*}{$\begin{array}{c}\text { Date } \\
\text { (DD. } \\
\text { MM. } \\
\text { YYYY) }\end{array}$} & \multirow[b]{2}{*}{ TAIEX } & \multirow{2}{*}{$\begin{array}{l}\text { Fluc- } \\
\text { tua- } \\
\text { tion }\end{array}$} & \multirow{2}{*}{$\begin{array}{c}\text { Fuz- } \\
\text { zi- } \\
\text { fied }\end{array}$} & \multirow{2}{*}{\begin{tabular}{c|} 
Date \\
(DD. \\
MM. \\
YYYY) \\
\end{tabular}} & \multirow[b]{2}{*}{ TAIEX } & \multirow{2}{*}{$\begin{array}{l}\text { Fuc- } \\
\text { tua- } \\
\text { tion }\end{array}$} & \multirow{2}{*}{$\begin{array}{c}\text { Fuz- } \\
\text { zi- } \\
\text { fied }\end{array}$} & \multirow{2}{*}{$\begin{array}{c}\text { Date } \\
\text { (DD. } \\
\text { MM. } \\
\text { YYYY) }\end{array}$} & \multirow[b]{2}{*}{ TAIEX } & \multirow{2}{*}{$\begin{array}{l}\text { Fluc- } \\
\text { tua- } \\
\text { tion }\end{array}$} & \multirow{2}{*}{$\begin{array}{c}\text { Fuz- } \\
\text { zi- } \\
\text { fied }\end{array}$} \\
\hline & & & & & & & & & & & \\
\hline 03.04 .1999 & 7182.2 & -50.31 & 3 & 06.05 .1999 & 7560.05 & -12.11 & 4 & 05.06.1999 & 7639.3 & 48.86 & 5 \\
\hline 06.04 .1999 & 7163.99 & -18.21 & 4 & 07.05 .1999 & 7469.33 & -90.72 & 3 & 07.06 .1999 & 7802.69 & 163.39 & 6 \\
\hline 07.04 .1999 & 7135.89 & -28.1 & 4 & 10.05 .1999 & 7484.37 & 15.04 & 4 & 08.06 .1999 & 7892.13 & 89.44 & 5 \\
\hline 08.04.1999 & 7273.41 & 137.52 & 6 & 11.05 .1999 & 7474.45 & -9.92 & 4 & 09.06 .1999 & 7957.71 & 65.58 & 5 \\
\hline 09.04 .1999 & 7265.7 & -7.71 & 4 & 12.05 .1999 & 7448.41 & -26.04 & 4 & 10.06 .1999 & 7996.76 & 39.05 & 4 \\
\hline 12.04 .1999 & 7242.4 & -23.3 & 4 & 13.05 .1999 & 7416.2 & -32.21 & 4 & 11.06 .1999 & 7979.4 & -17.36 & 4 \\
\hline 13.04 .1999 & 7337.85 & 95.45 & 5 & 14.05 .1999 & 7592.53 & 176.33 & 6 & 14.06 .1999 & 7973.58 & -5.82 & 4 \\
\hline 14.04 .1999 & 7398.65 & 60.8 & 5 & 15.05 .1999 & 7576.64 & -15.89 & 4 & 15.06 .1999 & 7960 & -13.58 & 4 \\
\hline 15.04 .1999 & 7498.17 & 99.52 & 5 & 17.05 .1999 & 7599.76 & 23.12 & 4 & 16.06 .1999 & 8059.02 & 99.02 & 5 \\
\hline 16.04 .1999 & 7466.82 & -31.35 & 4 & 18.05 .1999 & 7585.51 & -14.25 & 4 & 17.06.1999 & 8274.36 & 215.34 & 7 \\
\hline 17.04 .1999 & 7581.5 & 114.68 & 5 & 19.05 .1999 & 7614.6 & 29.09 & 4 & 21.06 .1999 & 8413.48 & 139.12 & 6 \\
\hline 19.04 .1999 & 7623.18 & 41.68 & 4 & 20.05 .1999 & 7608.88 & -5.72 & 4 & 22.06 .1999 & 8608.91 & 195.43 & 6 \\
\hline 20.04 .1999 & 7627.74 & 4.56 & 4 & 21.05 .1999 & 7606.69 & -2.19 & 4 & 23.06 .1999 & 8492.32 & -116.59 & 3 \\
\hline 21.04 .1999 & 7474.16 & -153.58 & 2 & 24.05 .1999 & 7588.23 & -18.46 & 4 & 24.06 .1999 & 8589.31 & 96.99 & 5 \\
\hline 22.04 .1999 & 7494.6 & 20.44 & 4 & 25.05 .1999 & 7417.03 & -171.2 & 2 & 25.06 .1999 & 8265.96 & -323.35 & 1 \\
\hline 23.04 .1999 & 7612.8 & 118.2 & 5 & 26.05 .1999 & 7426.63 & 9.6 & 4 & 28.06 .1999 & 8281.45 & 15.49 & 4 \\
\hline 26.04 .1999 & 7629.09 & 16.29 & 4 & 27.05 .1999 & 7469.01 & 42.38 & 5 & 29.06 .1999 & 8514.27 & 232.82 & 7 \\
\hline 27.04 .1999 & 7550.13 & -78.96 & 3 & 28.05 .1999 & 7387.37 & -81.64 & 3 & 30.06 .1999 & 8467.37 & -46.9 & 3 \\
\hline 28.04 .1999 & 7496.61 & -53.52 & 3 & 29.05 .1999 & 7419.7 & 32.33 & 4 & 02.07 .1999 & 8572.09 & 104.72 & 5 \\
\hline 29.04 .1999 & 7289.62 & -206.99 & 2 & 31.05 .1999 & 7316.57 & -103.13 & 3 & 03.07.1999 & 8563.55 & -8.54 & 4 \\
\hline 30.04 .1999 & 7371.17 & 81.55 & 5 & 01.06 .1999 & 7397.62 & 81.05 & 5 & 05.07 .1999 & 8593.35 & 29.8 & 4 \\
\hline 03.05 .1999 & 7383.26 & 12.09 & 4 & 02.06 .1999 & 7488.03 & 90.41 & 5 & 06.07 .1999 & 8454.49 & -138.86 & 2 \\
\hline 04.05 .1999 & 7588.04 & 204.78 & 6 & \begin{tabular}{|l|}
03.06 .1999 \\
\end{tabular} & \begin{tabular}{|l|}
7572.91 \\
\end{tabular} & 84.88 & 5 & 07.07 .1999 & 8470.07 & 15.58 & 4 \\
\hline 05.05 .1999 & 7572.16 & -15.88 & 4 & 04.06 .1999 & 7590.44 & 17.53 & 4 & 08.07.1999 & 8592.43 & 122.36 & 5 \\
\hline 09.07.1999 & 8550.27 & -42.16 & 3 & 09.08 .1999 & 7028.01 & -21.73 & 4 & 08.09.1999 & 7973.3 & 27.54 & 4 \\
\hline 12.07 .1999 & 8463.9 & -86.37 & 3 & 10.08 .1999 & 7269.6 & 241.59 & 7 & 09.09 .1999 & 8025.02 & 51.72 & 5 \\
\hline 13.07 .1999 & 8204.5 & -259.4 & 1 & 11.08 .1999 & 7228.68 & -40.92 & 4 & 10.09 .1999 & 8161.46 & 136.44 & 6 \\
\hline 14.07 .1999 & 7888.66 & -315.84 & 1 & 12.08 .1999 & \begin{tabular}{|l|}
7330.24 \\
\end{tabular} & 101.56 & 5 & 13.09 .1999 & 8178.69 & 17.23 & 4 \\
\hline 15.07 .1999 & 7918.04 & 29.38 & 4 & 13.08 .1999 & 7626.05 & 295.81 & 7 & 14.09 .1999 & 8092.02 & -86.67 & 3 \\
\hline 16.07 .1999 & 7411.58 & -506.46 & 1 & 16.08 .1999 & 8018.47 & 392.42 & 7 & 15.09 .1999 & 7971.04 & -120.98 & 3 \\
\hline 17.07 .1999 & 7366.23 & -45.35 & 3 & 17.08.1999 & 8083.43 & 64.96 & 5 & 16.09 .1999 & 7968.9 & -2.14 & 4 \\
\hline 19.07 .1999 & 7386.89 & 20.66 & 4 & 18.08 .1999 & 7993.71 & -89.72 & 3 & 17.09 .1999 & 7916.92 & -51.98 & 3 \\
\hline 20.07 .1999 & 7806.85 & 419.96 & 7 & 19.08 .1999 & 7964.67 & -29.04 & 4 & 18.09 .1999 & 8016.93 & 100.01 & 5 \\
\hline 21.07 .1999 & 7786.65 & -20.2 & 4 & 20.08 .1999 & 8117.42 & 152.75 & 6 & 20.09 .1999 & 7972.14 & -44.79 & 3 \\
\hline
\end{tabular}


Table A1 (c o n t in u e d)

\begin{tabular}{|c|c|c|c|c|c|c|c|c|c|c|c|}
\hline \multirow{2}{*}{$\begin{array}{c}\text { Date } \\
\text { (DD. } \\
\text { MM. } \\
\text { YYYY) }\end{array}$} & \multirow[b]{2}{*}{ TAIEX } & \multirow{2}{*}{$\begin{array}{l}\text { Fuc- } \\
\text { tua- } \\
\text { tion }\end{array}$} & \multirow{2}{*}{$\begin{array}{l}\text { Fuz- } \\
\text { zi- } \\
\text { fied }\end{array}$} & \multirow{2}{*}{$\begin{array}{c}\text { Date } \\
\text { (DD. } \\
\text { MM. } \\
\text { YYYY) }\end{array}$} & \multirow[b]{2}{*}{ TAIEX } & \multirow{2}{*}{$\begin{array}{l}\text { Fluc- } \\
\text { tua- } \\
\text { tion }\end{array}$} & \multirow{2}{*}{$\begin{array}{c}\text { Fuz- } \\
\text { zi- } \\
\text { fied }\end{array}$} & \multirow{2}{*}{$\begin{array}{c}\text { Date } \\
\text { (DD. } \\
\text { MM. } \\
\text { YYYY) }\end{array}$} & \multirow[b]{2}{*}{ TAIEX } & \multirow{2}{*}{$\begin{array}{l}\text { Fluc- } \\
\text { tua- } \\
\text { tion }\end{array}$} & \multirow{2}{*}{$\begin{array}{c}\text { Fuz- } \\
\text { zi- } \\
\text { fied }\end{array}$} \\
\hline & & & & & & & & & & & \\
\hline 22.07 .1999 & 7678.67 & -107.98 & 3 & 21.08.1999 & 8153.57 & 36.15 & 4 & 27.09.1999 & 7759.93 & -212.21 & 1 \\
\hline 23.07 .1999 & 7724.52 & 45.85 & 5 & 23.08.1999 & 8119.98 & -33.59 & 4 & 28.09 .1999 & 7577.85 & -182.08 & 2 \\
\hline 26.07 .1999 & 7595.71 & -128.81 & 2 & 24.08.1999 & 7984.39 & -135.59 & 2 & 29.09 .1999 & 7615.45 & 37.6 & 4 \\
\hline 27.07.1999 & 7367.97 & -227.74 & 1 & 25.08.1999 & 8127.09 & 142.7 & 6 & 30.09 .1999 & 7598.79 & -16.66 & 4 \\
\hline 28.07.1999 & 7484.5 & 116.53 & 5 & 26.08.1999 & 8097.57 & -29.52 & 4 & 01.10.1999 & 7694.99 & 96.2 & 5 \\
\hline 29.07 .1999 & 7359.37 & -125.13 & 3 & 27.08.1999 & 8053.97 & -43.6 & 3 & 02.10.1999 & 7659.55 & -35.44 & 4 \\
\hline 30.07 .1999 & 7413.11 & 53.74 & 5 & 30.08 .1999 & 8071.36 & 17.39 & 4 & 04.10 .1999 & 7685.48 & 25.93 & 4 \\
\hline 31.07 .1999 & 7326.75 & -86.36 & 3 & 31.08 .1999 & 8157.73 & 86.37 & 5 & 05.10.1999 & 7557.01 & -128.47 & 2 \\
\hline 02.08 .1999 & 7195.94 & -130.81 & 2 & 01.09.1999 & 8273.33 & 115.6 & 5 & 06.10 .1999 & 7501.63 & -55.38 & 3 \\
\hline 03.08.1999 & 7175.19 & -20.75 & 4 & 02.09 .1999 & 8226.15 & -47.18 & 3 & 07.10.1999 & 7612 & 110.37 & 5 \\
\hline 04.08 .1999 & 7110.8 & -64.39 & 3 & 03.09.1999 & 8073.97 & -152.18 & 2 & 08.10.1999 & 7552.98 & -59.02 & 3 \\
\hline 05.08.1999 & 6959.73 & -151.07 & 2 & 04.09 .1999 & 8065.11 & -8.86 & 4 & 11.10 .1999 & 7607.11 & 54.13 & 5 \\
\hline 06.08 .1999 & 6823.52 & -136.21 & 2 & 06.09 .1999 & 8130.28 & 65.17 & 5 & 12.10.1999 & 7835.37 & 228.26 & 7 \\
\hline 07.08.1999 & 7049.74 & 226.22 & 7 & 07.09.1999 & 7945.76 & -184.52 & 2 & 13.10 .1999 & 7836.94 & 1.57 & 4 \\
\hline 14.10.1999 & 7879.91 & 42.97 & 5 & 20.10 .1999 & 7666.64 & -26.32 & 4 & 27.10.1999 & 7701.22 & 0.93 & 4 \\
\hline 15.10.1999 & 7819.09 & -60.82 & 3 & 21.10.1999 & 7654.9 & -11.74 & 4 & 28.10 .1999 & 7681.85 & -19.37 & 4 \\
\hline 16.10 .1999 & 7829.39 & 10.3 & 4 & 22.10.1999 & 7559.63 & -95.27 & 3 & 29.10 .1999 & 7706.67 & 24.82 & 4 \\
\hline 18.10 .1999 & 7745.26 & -84.13 & 3 & 25.10.1999 & 7680.87 & 121.24 & 5 & 30.10 .1999 & 7854.85 & 148.18 & 6 \\
\hline 19.10.1999 & 7692.96 & -52.3 & 3 & 26.10 .1999 & 7700.29 & 19.42 & 4 & & & & \\
\hline
\end{tabular}

Table A2. The transition relationship matrix TRM

\begin{tabular}{|c|c|c|c|c|c|c|c|}
\hline Fuzzy set & 1 & 2 & 3 & 4 & 5 & 6 & 7 \\
\hline 11 & 0.14 & 0.14 & 0.14 & 0.43 & 0.14 & 0.00 & 0.00 \\
\hline 12 & 0.06 & 0.06 & 0.12 & 0.47 & 0.18 & 0.06 & 0.06 \\
\hline 13 & 0.05 & 0.12 & 0.20 & 0.32 & 0.27 & 0.02 & 0.02 \\
\hline 14 & 0.02 & 0.07 & 0.20 & 0.38 & 0.20 & 0.09 & 0.05 \\
\hline 15 & 0.02 & 0.07 & 0.24 & 0.31 & 0.18 & 0.09 & 0.09 \\
\hline 16 & 0.00 & 0.00 & 0.07 & 0.57 & 0.21 & 0.07 & 0.07 \\
\hline 17 & 0.00 & 0.08 & 0.15 & 0.38 & 0.15 & 0.08 & 0.15 \\
\hline
\end{tabular}


Table A3. The normalized transition relationship matrix $\mathrm{FTRM}^{n}$

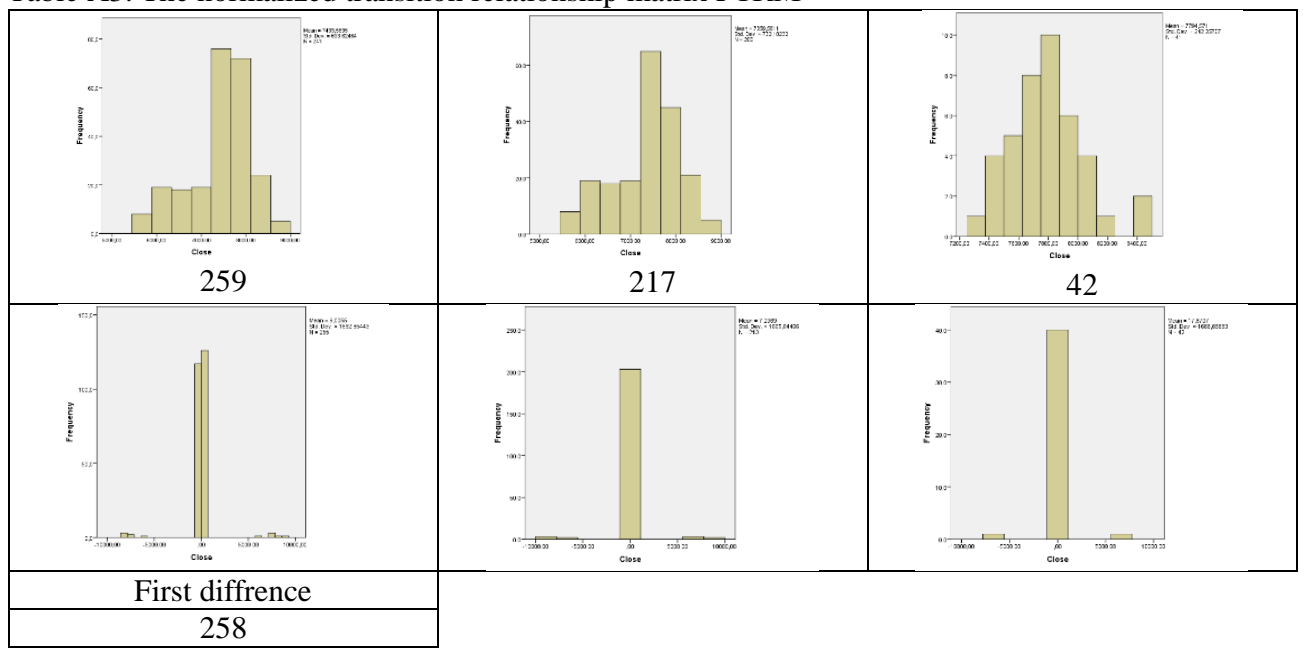

Received: 10.12.2018; Second Version: 14.02.2019; Accepted: 18.04.2019 